\title{
TNL
}

White, Amanda. "The Daily Haiku: Introduction."

Transnational Literature, Vol. 13, Issue 1, October 2021

DOI: https://doi.org/10.33008/TNL.2021.13015

URL: https://transnationalliterature.org/

\section{The Daily Haiku: Introduction}

\section{Amanda White}

As the Covid-19 pandemic descended across the world, and in the UK, in March 2020, a lockdown order was issued, I wanted to explore the possibility of remapping a sense of community through everyday creativity, using an approach that would be accessible, engaging and fun. With the retraction of our physical space, our mental health was also impacted. Without opportunities to meet physically, suddenly the chance to reopen horizons emerged through the possibility of building an online global community, coalescing around haiku.

Alongside my own writing, I have also worked as a creative practitioner focusing on arts for health, and one of my favourite workshops in any setting is 'Are you a leaf or a tree?', which culminates in creating a haiku. Despite having no social media experience, I embraced Facebook's readymade group template and fixed on the format of 'The Daily Haiku' with a daily theme to encourage engagement, as well as the opportunity to include images (photographs, artwork or video). I wanted to appeal to people who had never written before, those returning to writing, and also experienced writers. Amazingly that is what we have become. Starting with just one member in rural west Cornwall, we now have $10000+$ members worldwide, and we are still growing.

We have been able to foster a nurturing, supportive and creative community by making that community the driving force in shaping the group. Decisions are made collaboratively and themes or prompts are decided with polls. Many of our regular features began as suggestions from the members, including our renga evenings, weekly themes, famous weekend haiku thread, haiga feature and most recently the addition of a weekly season word, and regular photo prompts from an image bank created by members. The Great Margin Conversation blog post has offered another platform to share articles on writing, haiku, wellbeing, and crucially to publish the interviews with members of The Daily Haiku featured here. Connecting through sharing our haiku continues to be not only inspiring, but also something that has helped to promote wellbeing. Often, very personal feelings are shared within the group and members respond with kindness and support, and are encouraged to share their own feelings in return.

Being an online group has allowed us to grow beyond the South West and national boundaries to become a richly diverse community, which enhances all our engagement immensely. I think having an easily understandable format has been key and the option to add images has encouraged people not only from other creative areas to get involved, but also visual thinkers who approach writing from different perspectives. Many of the members have said that we are a particularly welcoming and friendly space, which was my aim, as I feel some writing groups can become elitist and prescriptive. I feel we are also an incubator that is really encouraging people to explore their writing and develop 
their voice. Several members are publishing their work and blogging. We are keen to develop more opportunities for members to share their work. Our film initiatives have been very rewarding and bonding for members, firstly, through the ' 100 Days of Haiku' film project and, later, the film series ' Even Dream in Haiku', which was produced in collaboration with Paper Nations.

A wider conversation has also started that is bringing people from different parts of the globe together, to not only create haiku but also to chat, debate and share ideas. Thus, from displacement we meet in a virtual place that we can all access. Early on, feedback emerged that highlighted The Daily Haiku as a place that anchored people physically as well as mentally. This element of emotional wellbeing helped to shape and grow our community, where members are not only involved in creative activities, but those same activities are also inextricably linked to a sense of wellbeing. The easily understandable format, welcoming atmosphere and clear weekly formats at The Daily Haiku allow members to 'travel' with their words and connect across cultures. However, making sure we do not stay still is also key in enabling members to be actively involved in creating work and also creating the direction the community is taking. In this way, I am always asking 'where do you want to go today?' offering possibility during a time when restrictions might otherwise be limiting our creative, social and physical horizons.

\section{Amanda White}

Amanda White is a writer and creative practitioner working in education, community, healthcare and corporate settings. She moved from London, where she also worked as a literary agent, to Cornwall with her young family twenty years ago. Her poetry collections are published by Flambard Press, and children's books by Barefoot Books. She makes short films with director Andrew Gillman and, last March, set up The Daily Haiku, which now has over 10,000 members worldwide. 